\title{
Anaesthesia for Caesarean section in a parturient with quintuplet gestation, pulmonary oedema and thrombocytopaenia
}

The case of a 32-year-old parturient with a quiniuplet pregnancy is described. The pregnancy had been complicated by premature labour which was treated with ritodrine tocolysis. Betamethasone was administered to hasten feral lung maturation. The ritodrine therapy was complicated with fluid overload and pulmonary oedema requiring intravenous diuretic treatment. The patient presented urgently for Caesarean section, with fluid overload and worsening thrombocjtopaenia. Life-threatening pulmonary oedema was manifest in the immediate preinduction period, following insertion of a pulmonary artery catheter and surgery was delayed to improve the mother's condition with intravenous diuretic therapy. Induction was carried out with the patient in the sitting position, with cricoid pressure maintained to protect the airway as the patient was lowered to a wedged, supine position. Intravenous nitroglycerin was used to control blood pressure. Low pressure mask-bag ventilation was utitized to maintain oxygen saturation and the patient was intubated and ventilated with positive end -expiratory pressurc. Positive pressure ventilation was continued for 24 hours postoperatively. The perioperative course is reviewed and followed by a discussion of the anaesthetic considerations for multiple gestation pregnancies.

\section{Key words:}

ANAESTHESIA: obstetric; COMPLICATIONS: preterm labour, multiple gestation, pulmonary oedema; SYMPATHETIC NERVOUS SYSTEM, SYMPATHOMIMETIC AGENTS: ritodrine, beta-mimetics.

From the Department of Anaesthesia, Ottawa General Hospital, 501 Smyth Road, Ottawa, Ontario, K1H 8L6.

Address carrespondence to: $\mathrm{Dr}$. Elliott.
Multiple gestation pregnancies are fraught with risk for both mother and fetuses. Maternal mortidity and mortality are increased compared with singleton pregnancies. The incidence of fetal and neonatal demise is increased as well, and premature labour and delivery appears to be the single most important factor responsible. Premature Jabour is a common complication of pregnancy in the parturient with a multiple gestation. Therapy for preterm labour includes both agents to inhibit uterine contractions as well as agents to increase fetal lung surfactant production, facilitating fetal lung maturation. These agents are not without side-effects and life-threatening complications have been reported. We present the case of a parturient with a quintuplet gestation complicated by preterm labour. Tocolysis, although successful in pro. longing labour by 14 days was complicated by maternal fluid overload and pulmonary oedema.

\section{Case report}

The patient, a 32 year-old female, Gravida 2, with a quintuplet pregnancy at 27 weeks gestational age, was admitted to hospital because of an effacing cervix. She went into premature labor on the day of admission and tocolysis was initiated with intravenous ritodrine, while betamethasone was administered to hasten fetal lung maturation. For the next 14 days, up to and including the day of delivery, tocolysis was maintained with ritodrine, administered either intravenously or crally. Early in the course of therapy the patient complained of dyspnoea and was noted to be gaining weight. Daily furosemide therapy was initiated to control fluid retention. Nine days before delivery, orthopnoea was evident and physical examination revealed pitting oedema to wais: level. Four days prior to delivery there was clinical evidence of pulmonary aedema and the furosemide dose was increased. The patient was now assuming a sitting posture around the clock, because any degree of recumbency caused dyspnoca. Despite worsening symptoms of pulmonary oedema, the 
patient resisted intervention in the form of operative delivery, hoping to increase gestational age for fetal optimization.

Six days prior to delivery thrombocytopenia of $109 \times$ $10^{9} \cdot \mathrm{L}^{-1}$ was noted on haematologic examination. When the platelet count dropped from $95 \times 10^{9} \cdot \mathrm{L}^{-1}$ to $72 \times$ $10^{9} \cdot \mathrm{L}^{-1}$ within a $24 \mathrm{hr}$ period, the decision to proceed to Caesarean delivery was made.

A planning committec had been formed in anticipation of the quintuplet delivery. Representatives from the Departments of Obstetrics, Pediatrics, Neonatology, Anaesthesia, Nursing Services and Respiratory Technology had met to ensure availability of both manpower and equipment for the birth. The existing twin-isolette neonatal resuscitation room was augmented by equipping an adjacent delivery room to receive three of the five quints. Teams of neonatologists, neonatal intensive care nurses and respiratory technologists were available to care for the newborns.

The patient was brought into the delivery/operating room. Electrocardiographic leads and a blood pressure cuff as well as a pulse oximeter were placed. Initial blood presure and heart rate were $160 / 110 \mathrm{mmHg}$ and 120 beats $\cdot \min ^{-1}$ respectively. A large bore intravenous line and a left radial artery line were established with local anaesthesia. The mother was positioned in $30^{\circ}$ reverse Trendelenberg position, with a wedge under her right hip, and the right internal jugular vein was cannulated and a pulmonary artery catheter inserted. During insertion of the central line, despite continuous administration of oxygen by mask, the patient complained of increasing dyspnoea. Following insertion of the pulmonary arery catheter, the patient was retumed to the sitting position. She was noted to be clinically cyanosed with a pulse oximeter saturation reading of 82 per cent $\left(\mathrm{SaO}_{2}\right)$. She was both hypertensive and tachycardiac at $160 / 100$ $\mathrm{mmHg}$ and 130 beats per minute, respectively. Crackles were auscultated to both shoulders, over anterior and posterior lung fields and she was coughing frothy, pinkish sputum.

A diagnosis of pulmonary oedema was made, the mask was exchanged for a non-rebreathing mask, furosemide $80 \mathrm{mg}$ was given intravenously and arterial blood gases were drawn. The $\mathrm{pH}$ was $7.39, \mathrm{PaCO}_{2} 33 \mathrm{mmHg}$ and $\mathrm{PaO}_{2} 52 \mathrm{mmHg}$. A brisk diuresis began almost immediately following the administration of furosemide and a second dose of furosemide, $40 \mathrm{mg}$ intravenously, was given 30 minutes after the first to sustain the diuresis. With diuresis of $1100 \mathrm{ml}$ there was improvement, both symptomatically and in the $\mathrm{SaO}_{2}$, which returned to 92 per cent. It was decided then to proceed with the induction.

The surgical team was asked to scrub and gown and the patient's abdomen was prepped while she remained sitting. Blood pressure prior to induction was $180 / 110$ $\mathrm{mnHg}$ and this was reduced to $140 / 90 \mathrm{mmHg}$ with 125 $\mu \mathrm{g}$ of intravenous nitroglycerin in three divided doses. The patient was anaesthetized in the sitting position, with cricoid pressure applied. Anaesthesia was induced with lidocaine $100 \mathrm{mg}$, thiopentone $300 \mathrm{mg}$ and succinylcholine $120 \mathrm{mg}$ IV. The patient lowered to the supine position and low-pressure, mask-bag ventilation was carried out while cricoid pressure was maintained $\mathrm{SaO}_{2}$ increased from 92 to 98 per cent and then intubation was carried out as the patient was being draped. Ventilation was controlled and 100 per cent oxygen was administered with positive end-expiratory pressure (PEEP) maintained. Isoflurane was administered at 0.4 per cent end-tidal concentration, monitored by mass spectrometer. A lower segment Caesarean section was carried out and the five fetuses were delivered without incident and in good condition. Approximately one litre of ascitic fluid was expelled from the peritoneal cavity upon opening of the peritoneum and blood loss was estimated at $1500 \mathrm{ml}$. Pulmonary artery wedge pressure measured after delivery of the infants was $24 \mathrm{mmHg}$.

Following delivery, the anaesthetic was converted to a balanced technique with fentanyl, vecuronium, nitrous oxide and oxygen. Haemodynamics were notably stable after induction and throughout the operative period. Repeat arterial blood gases intraoperatively, on controlled ventilation with PEEP, showed a pH of $7.34, \mathrm{PaCO}_{2}$ of 42 $\mathrm{mmHg}$ and $\mathrm{PaO}_{2}$ of $316 \mathrm{mmHg}$.

The patient was taken to the Recovery Room intubated and ventilated and, after it was ascertained that her condition was stable, she was transferred to the Intensive Care Unit. She was extubated on the second postoperative day, made an uncomplicated recovery and was discharged home on the ninth postoperative day.

\section{Discussion}

The perioperative course of our patient provides an excellent case study of the problems of the parturient with a multiple gestation pregnancy. Featured were: premature labour; beta-mimetic tocolysis complicated by fluid overload and pulmonary oedema; and pre-eclampsia. We shall discuss these features, as they apply to our patient and to the parturient with a multiple gestation pregnancy, in general.

The physiologic changes of pregnancy are well described. ${ }^{1,2}$ Increases in blood volume, red cell mass and cardiac output have been studied in singleton, twin and triplet pregnancies (Table I) ${ }^{3,4}$ For multiple gestations of higher order, little information is available, and extrapolation of existing twin-triplet data represents the best estimate for changes in cardiovascular parameters. With 
TABLE I Increases in cardiovascular parameters with pregnancy (per cent)

\begin{tabular}{llll}
\hline & Singleton & Twin & Tripiel \\
\hline Blood volume & 49 & 67 & 97 \\
Red cell mass & 31 & 40 & 50 \\
Cardrac output & 44 & 48 & 48 \\
\hline
\end{tabular}

regard to the respiratory system, it would be expected that the cephalad displacement of the diaphragm seen in the singleton pregnancy would be exaggerated in the multiple pregnancy resulting in further decreases in functional residual capacity and inspiratory capacity. Incompetence of the lower oesophageal sphincter would be expected to occur earlier in the gestation in the multiple pregnancy than in a singleton cohort, with obvious implications for anaesthesia practice.

Anaemia, toxaemia and haemornage, both antepartum and postpartum, are more common in parturients with a multiple gestation pregnancy. In a review of a series of triplet pregnancies, antepartum haemorrhage was seen in five per cent of pregnancies, pre-eclampsia in 19 per cent, anaemia in 14 per cent and pre-term labour in 78 per cent. ${ }^{5}$ The maternal mortality rate is increased two to three times compared with singleton pregnancies. ${ }^{6}$

Fetal loss in the multiple gestation pregnancy is very common. The combined stillbirth and neonatal mortality rate in a series of triplet pregnancies was reported as $232 / 1000$. Preterm labour and birth order were the two most important factors, relating to neonatal mortality, that were isolated. ${ }^{5}$ In a series of 1655 sets of twins mortality was somewhat higher compared to singletons. Placentae from the twin pregnancies were noted to be smaller than the singleton placentae from 21 to 22 weeks to term and there was some suggestion that the placenta was a factor limiting growth and gestational age in twin pregnancies. ${ }^{7}$

Premature labour is more common than term labour in multiple gestation pregnancies. Up to 60 per cent of twins and 80 per cent of triplets are premature. Because prematurity is the most important risk factor leading to stillbirth and neonatal mortality, there is great effort directed towards treating preterm labour and prolonging gestation. The incidence of both respiratory distress syndrome and neonatal mortality are reduced when premature labour is treated at less than 33 weeks gestation. ${ }^{9}$ Beta-mimetic agents for labour tocolysis, combined with corticosteroids to hasten fetal lung maturation, represent the most utilized mode of treatment for preterm labour.

Ritodrine, a beta-adrenergic agonist, with predominant beta $_{2}$ specificity, has been demonstrated, in multiple studies, to be more effective than placebo in the treatment of preterm labour. ${ }^{8}$ Ritodrine acts by increasing intracellular concentrations of CAMP, via activation of adenyl cyclase. The increased levels of cAMP inhibit myosin light chain kinase, interfere with actin-myosin coupling and result in uterine relaxation. Ritodrine tocolysis is not without side-cffects. Hyperglycaemia, hypokalaemia, fluid overload with dilutional anaemia and pulmonary oedema, hypotension, cardiac arrhythmias and myocardial ischaemia have all been reported in patients treated with ritodrine.

Ritodrine leads to sodium and water retention, expanding extracellular space and, in some patients, results in pulmonary oedema. Patients treated with ritodrine demonstrate positive fluid balance when compared to controls. ${ }^{10}$ When ritodrine is delivered in a saline vehicle, this positive fluid balance is augmented. In a study comparing saline and glucose solutions for ritodrine administration, there was a significantly increased incidence of matemal pulmonary oedema in the group receiving saline. ${ }^{11}$ There have been case reports as well as a retrospective study suggesting that the combination of corticosteroids and beta-mimetic agents increases the risk of maternal pulmonary oedema. ${ }^{32,13}$ However, there does not appear to be enhanced fluid retention caused by combination therapy compared to ritodrine treatment alone, when studied prospectively. ${ }^{11}$ Twin gestation appears to predispose the mother to the development of pulmonary oedema while being treated with the betamimetic agent, terbutaline. ${ }^{13}$ Finally, there have been case reports of maternal pulmonary oedema, during ritodrine therapy for preterm labour, in patients in whom there was no evidence of fluid overload. This suggests the potential for either non-cardiogenic pulmonary oedema with capillary leak or alternatively, myocardial failure. ${ }^{14,15}$ Strict intake and output measurements, daily weights and frequent examination for evidence of fluid overload or pulmonary oedema should be routine care for all patients on ritodrine therapy.

Ritodrine inhibits hypoxic pulmonary vasoconstriction and loss of this physiologic compensation in a parturient with pulmonary oedema may lead to increased ventilation-perfusion inequalities, with hypoxaemia out of proportion to the existing pulmonary oedema. ${ }^{16}$ Close monitoring of arterial oxygen content is mandatory in paticats undergoing ritodrine tocolysis, especially if it is complicated by maternal pulmonary oedema.

Arrhythmias, with and without evidence of myocardial ischaemia, have been reported in patients on ritodrine. ${ }^{9}$ Included have been premature ventricular contraction, premature nodal contraction and atrial fibrillation. These arrhythmias have responded to withdrawal of the drug and oxygen therapy. Previously undiagnosed cardiac lesions have been unmasked by beta-mimetic therapy, including atrial septal defects and idiopathic hypertrophic subaortic stenosis. ${ }^{17}$ Myocardial ischaemia, infarction and mater- 
TABLE II Anaesthetic considerations in multiple pregnancy

\section{Maternal}

Physiologic changes of pregnancy augmented

Increased incidence of toxemia

Increased anaemia

Increased incidence premature labour

Prolonged labours

More frequent ante/postpartum haemorrhage

Matemal monality higher

Retained placentae more common

\section{Fetal}

Prematurity 6-10 times more common

Abnormal presentation more frequent

Perinatal mortality rate increased

Asphyxia more common

Small for gestational age

nal death have occurred during beta-mimetic therapy. ${ }^{18}$ Continuation of therapy in the setting of serious cardiac complications is contraindicated.

The hyperglycuemia associated with ritodrine therapy results from activation of hepatic phosphorylase and mobilization of hepatic glycogen. Ketoacidosis and subsequent fetal death have been reported during tocolytic therapy in an insulin-dependent diabetic parturient. ${ }^{10,20}$ Serum insulin levels are increased via beta-mimetic stimulation of the pancreatic islet cells and hypokalaemia may result from the insulin-mediated movement of potassium and glucose from the extracellular to the intracellular space. Glucose administration should be appropriately restricted in non-diabetic patients and insulin-dependent diabetics must be managed very cautiously. Evidence of ketoacidosis or maternal hyperglycaemia should prompt rapid intervention and correction.

When approaching a parturient such as described in our case presentation, consideration must be given to both mother and her tiny, dependent charges (Table II). Preoperative assessment must be thorough. In situ intravenous catheters should be sufficient to allow for rapid volume infusion, through fluid warmers, in anticipation of greater than usual blood loss. Fetal depression must be minimized by avoidance of long induction-delivery and uterine-incision-delivery times. Sufficient paediatric staff should be present to resuscitate the newborns, thus allowing the anaesthetist to pay undivided attention to the mother.

In acdition to the routine electrocardiographic, temperature and stethoscope monitoring, an arterial line is highly desirable. Central pressure monitoring is near mandatory in such seriously ill patients. Central venous pressure may not be a true reflection of left-sided filling pressures in seriously ill parturients and for this season, a pulmonary artery catheter may be the preferred central monitoring line. ${ }^{21}$
Air embolism has recently been demonstrated to be a common occurrence during Caesarean section. ${ }^{22}$ The potential for significant air embolism may be greater in the setting of the large multiply pregnant uterus and the generous hysterotomy used to facilitate extraction of the fetuses. The pulmonary artery catheter has proven to be a valuable tool in monitoring for occurrence of air embolism, enhancing the desirability of the pulmonary artery catheter as the central line.for monitoring. ${ }^{23}$

In patients recently treated with beta-mimetics for tocolysis, presenting for anaesthesia, consideration must be given to a heightened potential for arrhythmias as well as the abating vasodilatory effects of the beta-mimetic on the peripheral vasculature. Patients treated with betamimetics have an increased risk of arrhythmias at time of induction and anaesthetic agents with sympathomimetic effects should be avoided or used with great caution. ${ }^{8}$ As serum levels of the beta-mimetic decrease there is increased vascular tone, resulting in a fluid shift back to the central compartment, which when combined with recumbent positioning for surgery, may result in central compartment overload and pulmonary oedema at the time of induction or shortly thereafter. The ability to provide positive-pressure ventilation with positive-end-expiratory pressure should be present at time of induction.

A slow intravenous induction may be preferable to a rapid sequence induction in these patients. The airway should be protected with cricoid pressure and lowpressure mask-bag ventilation is preferred to apnoeic oxygenation in patients with borderline oxygen status. Positive-pressure, controlled ventilation with PEEP suppor, if necessary, is indicated. If pulmonary oedema presents preoperatively, a short delay and intravenous diuretic treatment may rapidly improve the mother's condition. A variable period of postoperative ventilation with PEEP support is warranted, as diuretic therapy progresses.

We have presented the case of a 32 year-old parturient with a quintuplet pregnancy. Premature labour and ritodrine therapy, complicated by significant volume overload and pulmonary oedema, as well as thrombocytopaenia and pre-eclampsia combined to yield a seriously ill parturient presenting for urgent Caesarean section. The degree of fluid overload and pulmonary oedema was underestimated preoperatively because of the patient's assumption of the sitting position for several days preoperatively. Supine positioning, modified by $30^{\circ}$ reverse Trendelenburg and left-lateral wedged positioning resulted in life-threatening pulmonary oedema. We have dcscribed our approach to this patient specifically and outlined some thoughts on perioperative management of these patients in general. 


\section{Acknowledgement}

We would like to thank Ms. Sylvie Galipeau for her assistance in preparing this manuscript.

\section{References}

1 Cheek $T G$, Gutsche BB. Maternal physiologic alterations during pregnancy. in: Anethesia for obstetrics. Schnider SM, Levinson G (Eds). 1987. Baltimorc: Williams \& Wilkins: $3-13$.

2 Albright $G A$, Joyce III TA, Ferguson II JE, Jones MA. Physiology of pregnancy. $1 n$ : Anesthesia in obstetrics Albright GA, Ferguson JE, Joyce, Stcvenson (Eds). 1986 Woburn; Butterworth: $41-79$.

3 Rovinsky $J R$, Jaffin $H$. Cardiovascular hemodynamics in pregnancy. 1, Blood and plasma volumes in multiple pregnancy. Am J Obstet Gynecol 1965: 93: 1-15.

4 Rovinsky $J R, J a f f i n H$. Cardiovascular hemodynamics in pregnancy. II. Cardiac Output and left ventricular work in multiple pregnancy. Am J Obstet Gynecol 1966; 95 : $781-6$.

5 itzkowic $D$. A survey of 59 triplet pregnancics. Br J Obstet Gynaecol 1979; 86: 23-8.

6 Writer WOR. Breech presentation and multiple pregnancy. Clinics in Anesthesiology 1986; 4:305-20.

7 Bleker OP, Breur W, Huidekoper BL. A study of birth weight, placental weight and mortality of twins as compared to singletons. Br J Obstet Gynaecol 1979; 86: 111-8.

8 Dailey $P A$. Anesthesia for preterm labour. In: Anesthesia for obstetrics. Schnider SM, Levinson G (Eds). 1987 Battimore; Williams \& Wilkins: 243-62.

9 Benedetti $T$ J. Maternal complications of parenteral B-sympathomimetic therapy for premature labor. Am J Obstet Gynecol 1983; 145: 1-6.

10 Hankins GD. Hauth JC, Kuehl TJ, Brans YW, Cunningham $F G$, Pierson $W$. Ritodrine hydrochloride infusion in pregnant baboons. Am J Obstet Gynecol 1983; 147 : 254-9.

11 Philipsen T, Eriksen PS, Lynggard F. Pulmonary edema following ritodrine-saline infusions in premature labor. Obstet Gynecol 1981; 58: 304-8.

12 Jacobs $M M$, Knight $A B$, Arias $F$. Matcmal pulmonary edema resulting from betamimetic and glucocorticoid therapy. Obstet Gynecol 1980; 56: 56-9.

13 Katz $M$, Robertson PA, Creasy $P K$. Cardiovascular com plicarions associated with terbutaline treatment for preterm labor. Am J Obstet Gynecol 1981; 58: 605-8.

14 Renedeni TJ, Hargrave JC, Rosene KA. Matcrnal pulmonary edema during premature labor inhibition. Obstet Gynecol 1982; 59: 33S -7S.

15 Wheeler AS, Patel KF, Spain J. Pulmonary edema during $\beta$-tocolytic therapy. Anesth Analg 1981; 60: 685-96.

16 Conover $W B$, Benumof $I I$, Key $T L$. Ritodrine inhibition of hypoxic pulmonary vasoconstriction. Am J Obstet Gynecol 1983; 146: 652-6.

17 Ron-ei $R$, Caspi E. Herman A, Schreyer $P$, Algom $M$, Schlezinger $Z$. Unexpected cardiac pathology in preg nant women treated with ritodrine. Obstet Gynecol 1983; 61: $10 S-12 S$.

18 Tye $\mathrm{XH}$, Desser KB, Benchimol A. Angina pectoris associated with terbutaline treatment for premature labor. JAMA 1980; 244: 692-3.

19 Cotton DB. Strassner HT, Lipsen LG, Goldstein DA. The effects of terbutaline on acid base, serum electrolytes and glucose homeostasis during management of pretem labor. Am J Obstet Gynecol 1981; 141: 617-23.

20 Schiltinnis MS, Aaronoudse JG. Fetal death associaled with severe ritodrine-induced ketoacidosis. Lancet 1980; 1: 1145.

21 Benedeti $T J$, Kates $R$, Williams $V$. Hemodynamic observations in severe pre-eclampsia complicated by pulmonary edema. Am J Obstet Gynecol 1985; 152; 330-4.

22 Malinow AM, Naulty JS, Hunt CO, Datto S, Ostheimer GW. Precordial ultrasonic monitoring during cesarian delivery. Anesthesiology 1987; 66: 816-9

23 Marshall $W K$, Bedford $R F$. Use of a pulmonary anery catheter for detection and treatment of venous air embolism. Anesthesiology 1980; 52: 131.

Résume

On présente le cas d' une femme de 32 ans enceinte de quintuplet. La grossesse fut compliquée par un travail prématuré qui fur traité par la ritodrine. La bétaméthasare fut administré afin d'accélérer le maturation pulmonaire foatale. Le traitement à la ritodrine fut compliqué par la surcharge volémique et un oedème pulmonaire requêrant l'administration de diurérique par voie intraveineuse. La patiente s'est présenté d̀ l'urgence pour une césarienne avec une surcharge voléntique et aggravation de sa thrombocytopénie. Un cedème aigu pulmonaire était manifeste avant l'induction et suite à l'insertion d'un cathéter dans l'artère pulmonaire la chinurgie fut retardé afin d' améliorer la condition de la même par des diurériques intraveinexx. L'induction fut faite en position assise avec une pression cricoilde maintenue afin de proteger les voies aériennes quand ia patiente fut mise en position couchée. La nitroglycérine intra. veineuse fut uilisée afin de controler la pression artérielle. La ventilation manuelle ou masque à basse pression a été utilisée afin de maintenir une saturation d'oxygère et la patiente fut intubée et ventilée avec la pression positive en fin d'expiration. La ventilation avec une pression positive en fin d' expiration fut continuée pour 24 heures dans la période postopératoire. Une revue de la période périopératoire est faite et ceci est suivi par une discussion des considérations anesthésiquex dans les cas de grossesse à gestation multiple. 